\title{
A Complete Genome Sequence of the Wood Stem Endophyte Bacillus velezensis BY6 Strain Possessing Plant Growth- Promoting and Antifungal Activities
}

\author{
Ping Zhang $\mathbb{D}$, Jian Diao $\mathbb{D}$, Guangqiang Xie $\mathbb{D}$, Ling Ma $\mathbb{D}$, and Lihai Wang \\ Heilongjiang Provincial Key Laboratory of Forest Sustainable Management and Environmental Microbial Engineering, \\ Northeast Forestry University, Harbin 150040, China \\ Correspondence should be addressed to Lihai Wang; wanglihai60@yeah.net
}

Received 12 August 2020; Revised 31 December 2020; Accepted 15 January 2021; Published 31 January 2021

Academic Editor: Siddharth Pratap

Copyright (c) 2021 Ping Zhang et al. This is an open access article distributed under the Creative Commons Attribution License, which permits unrestricted use, distribution, and reproduction in any medium, provided the original work is properly cited.

\begin{abstract}
An endophytic bacterium Bacillus velezensis BY6 was isolated from the wood stems of healthy Populus davidiana $\times$ P. alba var. pyramidalis (PdPap). The BY6 strain can inhibit pathogenic fungus Alternaria alternate in PdPap and promote growth of PdPap seedlings. In the present study, we used the Pacific Biosciences long-read sequencing platform, a single-molecule realtime (SMRT) technology for strain BY6, to perform complete genome sequencing. The genome size was 3,898,273 bp, the number of genes was 4,045 , and the average GC content was $47.33 \%$. A complete genome of strain BY6 contained 110 secondary metabolite gene clusters. Nine of the secondary metabolite gene clusters exhibited antifungal activity and promoted growth functions primarily involved in the synthesis of surfactin, bacteriocins, accumulated iron ions, and related antibiotics. Gene clusters provide genetic resources for biotechnology and genetic engineering, and enhance understanding of the relationship between microorganisms and plants.
\end{abstract}

\section{Introduction}

Populus davidiana $\times$ P. alba var. pyramidalis (PdPap) is the most commonly planted tree species in China. Its characteristics include rapid growth, resistance to drought, and tolerance to low temperatures. PdPap is a female clone; the catkin can fall off naturally, and it is a model species for studying woody plants [1]. With the continuous expansion of plantations under PdPap and degradation of the environment, incidence of leaf diseases caused by fungi is increasing, adversely affecting the growth of PdPap. Leaf blight is one of the fungal diseases of PdPap caused by Alternaria alternate [2]. Plant growth-promoting bacteria (PGPB) are frequently used to control plant leaf diseases. PGPB are a type of bacteria that can move freely and usually colonize the internal tissues of a plant. PGPB do not cause substantial damage to host plants, but they instead establish a harmonious symbiotic relationship with the plants [3]. PGPB can inhibit a variety of plant pathogenic fungi $[4,5]$, promote plant growth and development $[6,7]$, enhance plant abiotic stress tolerance
$[8,9]$, and regulate and improve the soil environment [10, 11]. Bacillus species of bacteria are essential members of PGPR and have been developed as biological agents in agriculture that are used to control various plant diseases [12].

Bacillus velezensis is an important member of the PGPR family. Several studies have revealed that $B$. velezensis as an effective bacterium can produce bacteriocins, bioactive compounds, and biosurfactant proteins [13]. Martínez-Raudales et al. [14] reported that a strain of B. velezensis $2 \mathrm{~A}-2 \mathrm{~B}$, can significantly inhibit the mycelial growth of pathogenic fungiPhytophthora capsici, Fusarium solani, Fusarium oxysporum, and Rhizoctonia solani in pepper, and the lowest inhibition rate was more than $60 \%$. Huang et al. [15] inoculated a strain of B. velezensis HYEB5-6, in the leaves of Euonymus japonicus in vitro and established that it significantly reduced the disease index of E. japonicus. In addition, Meng et al. reported that a strain of $B$. velezensis $\mathrm{BAC} 03$, can produce IAA, NH3, and ACC-deaminase and promote the growth of 9 types of crops including beets, carrots, cucumbers, pepper, potatoes, radish, squash, tomatoes, and turnips [16]. 


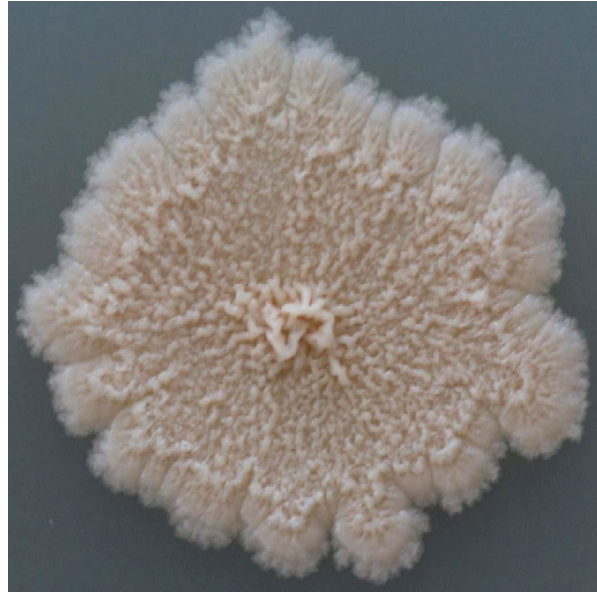

(a)

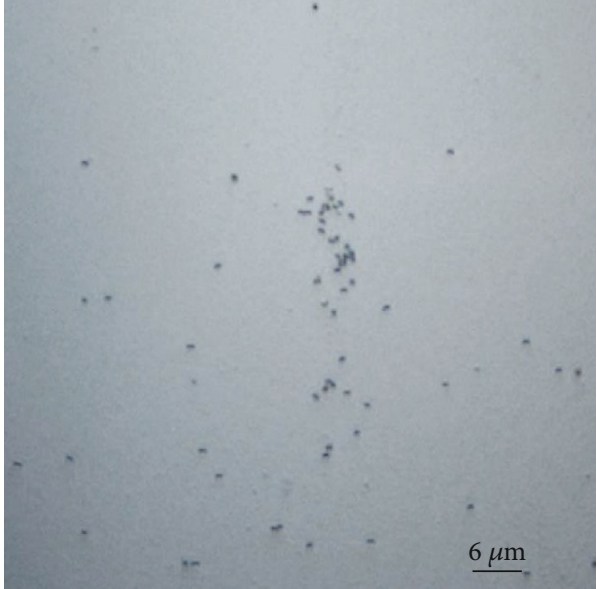

(b)

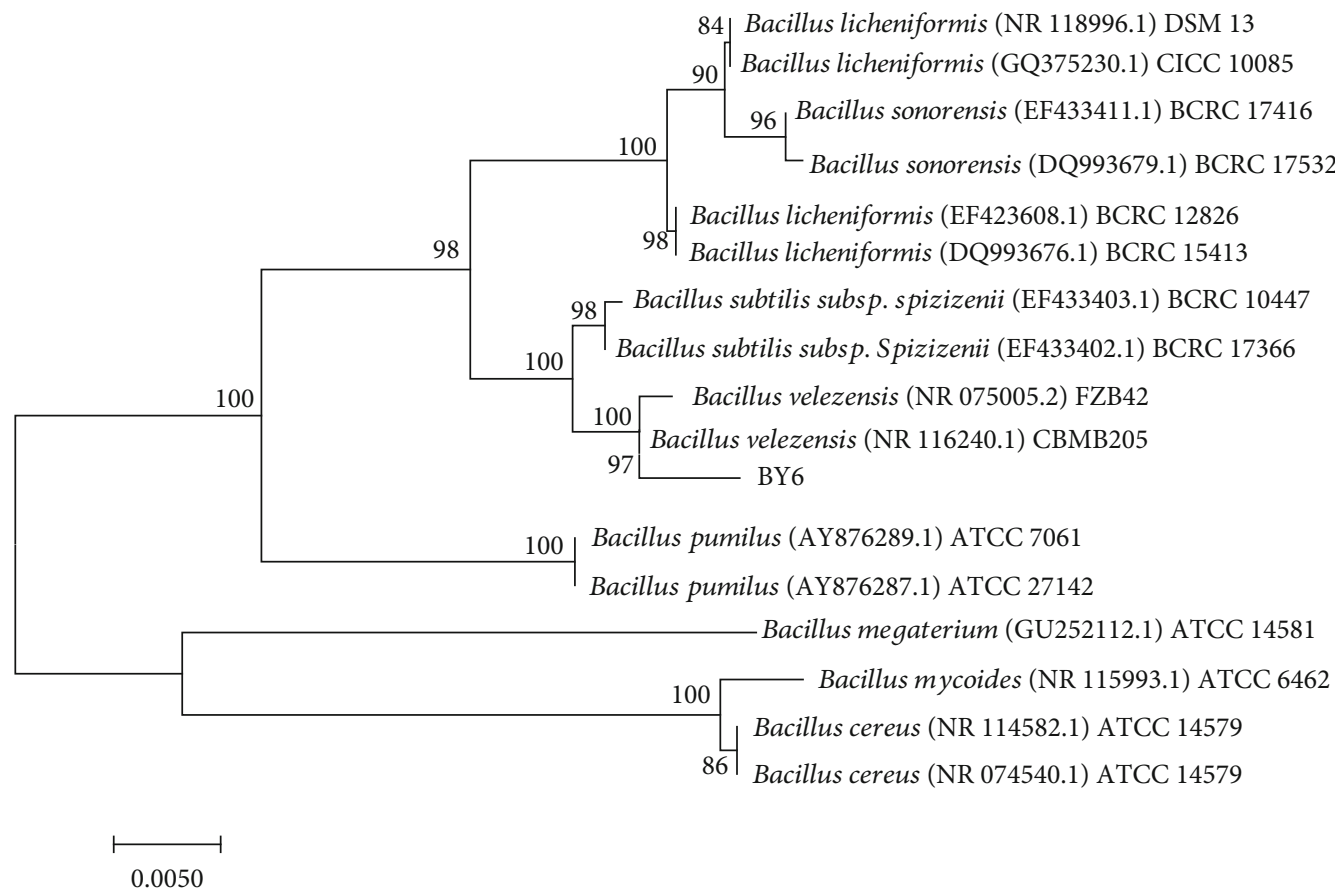

(c)

Figure 1: Morphological characteristics and phylogenetic tree of strain BY6. (a) Morphology of the colony. (b) Cell morphology and Gramstaining results. (c). The evolutionary tree constructed by CMEGA 6.0 software and calculation of evolution distance using the adjacency matrices; bootstrap values (expressed as percentages of 1000 replicates) are shown at branch points. The scale bar: 0.005 nucleotide substitution rate.

However, the biocontrol mechanisms of B. velezensis species as PGPR have not been clearly defined to date.

In the present study, we isolated and identified a beneficial strain BY6, that has antifungal effects against $A$. alternata and promotes the growth of PdPap. We used the Pacific Biosciences long-read sequencing platform single-molecule real-time (SMRT) technology for strain BY6 to perform complete genome sequencing and annotation to study the genetic basis and molecular mechanisms associated with biological control of the strain BY6. We identified particular secondary metabolic gene clusters for antimicrobial activity and genes linked to promoting plant growth.

\section{Materials and Methods}

2.1. Strain Isolation and Identification. The strain BY6 used in our study was isolated from the wood stems of healthy PdPap trees. A growth cone was used to drill into the wood stems of PdPap at a depth of approximately $30 \mathrm{~cm}$ (position was $1 \mathrm{~m}$ above the ground). The drilling cone and core puller of the growth cone were presterilized at high temperatures of $121^{\circ} \mathrm{C}$ for 20 mins. Afterwards, wood chips were quickly placed in a $5 \mathrm{~mL}$ sterile centrifuge tube. The wood chip samples were then loaded into a centrifuge tube placed in a water bath maintained at a constant temperature. The temperature of the water bath was increased and maintained at $90^{\circ} \mathrm{C}$ for 2 


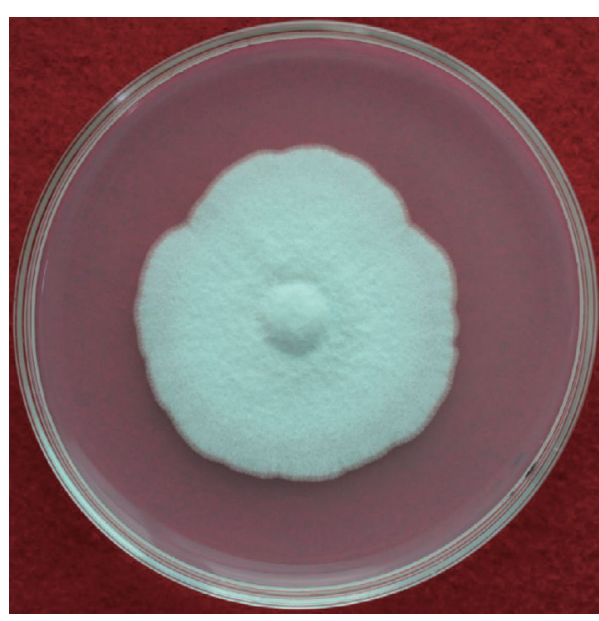

(a)

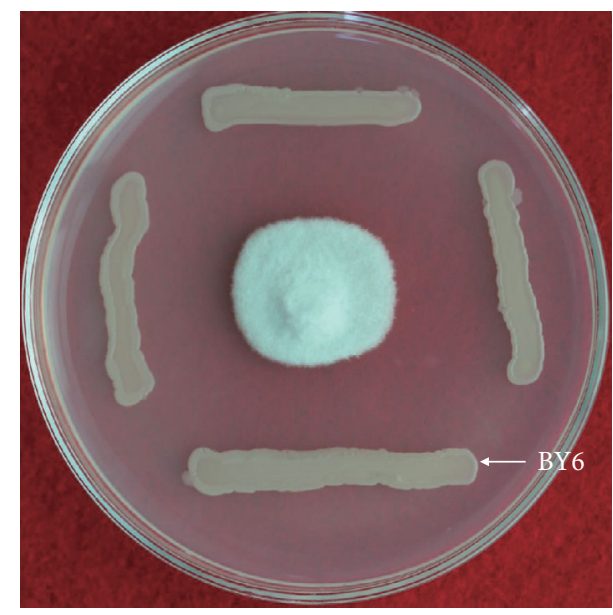

(b)

FIGURE 2: The inhibitory effect of strain BY6 on the growth of A. alternata colonies. (a) A. alternata colonies cultured separately in PDA medium. (b) Morphology of A. alternata colonies and simultaneous inoculation of BY6 in PDA medium. Procedure was repeated four times.

hours, taking advantage of the heat resistance of spores to eliminate nontarget bacteria. Wood chips were smeared on the surface of the Luria-Bertani (LB) plate 3 times by the streak culture method after natural cooling. The largest colony was transferred to a $1.5 \mathrm{~mL}$ cryovial containing $30 \%$ glycerol and stored at $-80^{\circ} \mathrm{C}$ after incubating samples for 4 days at $25^{\circ} \mathrm{C}$.

We identified the isolated strain. DNA was extracted using a bacterial DNA kit (Tiangen, Beijing, China). The amplification of 16S rRNA was performed according to the method described by Yamamoto and Harayama [17]. DNA amplification conditions were as follows: predenaturation was conducted at $94^{\circ} \mathrm{C}$ for 5 minutes, and the following procedures were performed after the first cycle: $94^{\circ} \mathrm{C}$ denaturation for 45 seconds, $55^{\circ} \mathrm{C}$ primer annealing for 45 seconds, and $72^{\circ} \mathrm{C}$ primer extension for 1 minute, 30 cycles. The last cycle was conducted at $72^{\circ} \mathrm{C}$ and extended again for 10 minutes. Products of the polymerase chain reaction (PCR) were sequenced by Shanghai Biotechnology Co. Ltd., and the sequencing results were compared with sequences from the National Center for Biotechnology Information (NCBI) database. A total of $16 \mathrm{~S}$ rRNA standard sequences were obtained from the GenBank database, and we subsequently used the neighbor-joining method of the MEGA 7.0 software package to construct a phylogenetic tree [18].

2.2. Determination of Antagonistic Properties. The antifungal activity of strain BY6 was tested with reference to the method by Chernin et al. [19]. A $5 \mathrm{~mm}$ diameter A. alternata cake was placed at the center of potato dextrose agar (PDA) plates followed by inoculation with the strain BY6 on the four sides of $A$. alternata at a distance of $2 \mathrm{~cm}$. Diameters of the fungal colonies were measured after 5 days using the cross method. Mycelial growth inhibition was calculated according to the formula: $\mathrm{MGI}(\%)=[$ (control colony diameter - treatment colony diameter $) /$ treatment group colony diameter $] \times 100$.

2.3. Plant Growth Promotion Activity of Strain BY6 on PdPap. We inoculated the strain BY6 in LB culture medium, and the culture was shaken at $160 \mathrm{rpm}$ at a temperature of $25^{\circ} \mathrm{C}$ for 5 days. Culture was centrifuged at $120,000 \mathrm{rpm}$ for $5 \mathrm{~min}$ at $4^{\circ} \mathrm{C}$ to remove the supernatant, and the bacterial cells were subsequently diluted with sterile water $\left(\mathrm{OD} \approx 1.8 \times 10^{8} \mathrm{CFU} / \mathrm{mL}\right)$. The treatment group was inoculated with $50 \mathrm{~mL}$ of bacterial cells per pot of PdPap by root irrigation, and the control group was inoculated with $50 \mathrm{~mL}$ of sterile water. PdPap seedlings were separated in advance using stem segments, and then transferred into the half-strength Murashige and Skoog (1/2 MS) macronutrient medium (culturing conditions were $30^{\circ} \mathrm{C}, 16 \mathrm{~h}$ light). PdPap seedlings were transplanted into a pot containing a mixture of black soil with a vermiculite ratio of $7: 3(v / v)$ after growing 3 to 5 leaves. The soil mixture used was autoclaved at $121^{\circ} \mathrm{C}$ for 2 hours before transplanting the seedlings. The seedlings were cultivated in a greenhouse with the following conditions: $25^{\circ} \mathrm{C}$, $16 \mathrm{~h}$ light: $8 \mathrm{~h}$ dark photoperiod, and $40 \%$ humidity. The seedlings were watered on a weekly basis with $50 \mathrm{~mL}$ of sterile water throughout the growth period. Thirty days after inoculating PdPap seedlings with BY6 according to the method described by Sanchez-Hernandez [20], we selected the 5th to 7 th leaves of plants from top to bottom and measured various physiological parameters including plant weight, leaf length, and number of roots.

2.4. Genome Sequencing, Assembly, and Annotation. We used the single-molecule real-time (SMRT) technology on the Pacific Biosciences sequencing platform to sequence the complete genome of strain BY6. The SMRT Link version 5.0.1 [21, 22] variant-calling software module was used for preliminary genome assembly, and arrow software was used to align the initial assembly results. GeneMarkS (version 4.17) software was used to predict protein-coding genes of the newly sequenced genome [22] (http://topaz.gatech.edu/ GeneMark/). We compared the protein sequences of the predicted genes to the protein database of Clusters of Orthologous Groups (COGs) (http://www.ncbi.nlm.nih.gov/COG) and obtained the corresponding COG annotation results [23]. BLAST software (blastx/blastp 2.2.24+) was used to 

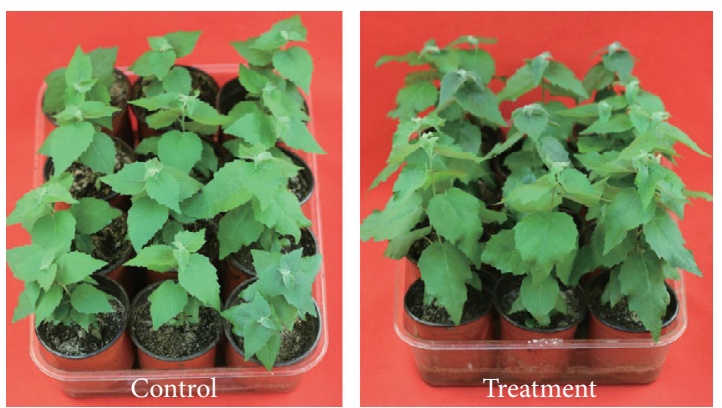

(a)

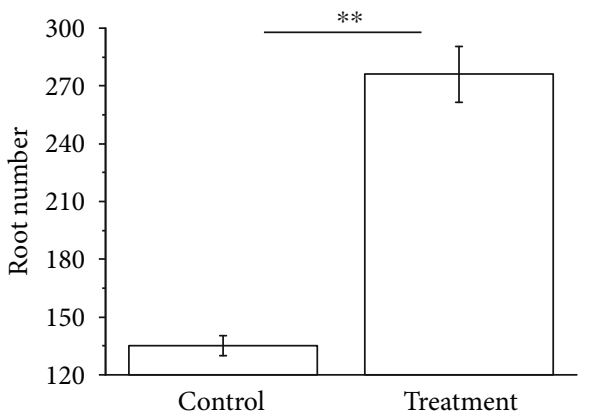

(c)

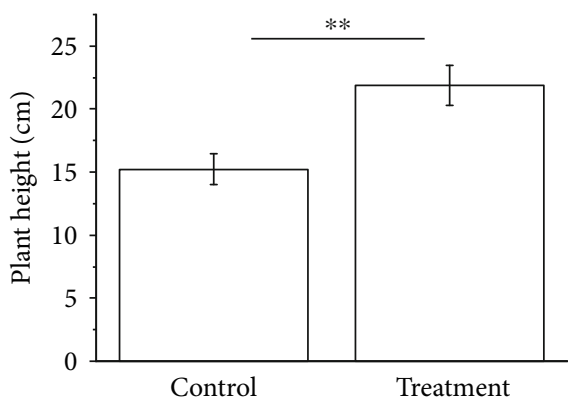

(b)
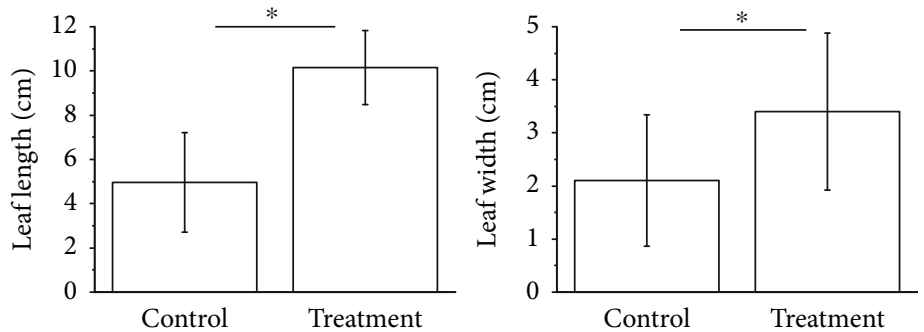

(d)

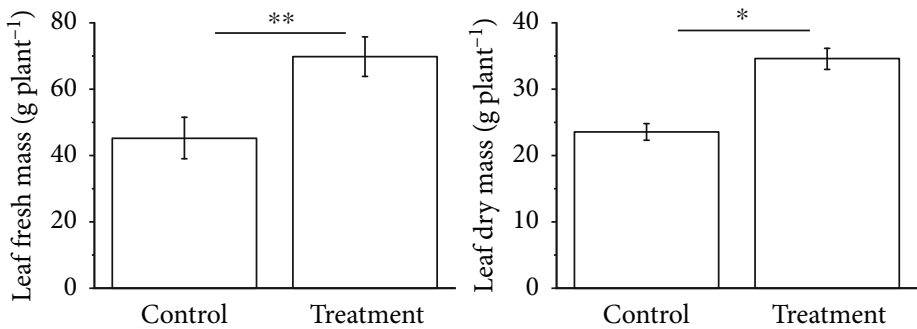

(e)

Figure 3: The effect of strain BY6 in promoting growth of PdPap seedlings. (a) Strain BY6 promoted growth of PdPap seedlings under the described soil culture conditions. (b) Heights of PdPap plants. (c) Root numbers of PdPap plants. (d) Length and width of leaves. (e) Fresh and dry weight of leaves. The graphical values are the average of 4 biological repeats. Error bars represent standard errors of the mean $(n=4)$ at each time point; $*$ indicates significant difference between treatments, $P<0.05$, and $* *$ indicates a significant difference between treatments, $P<0.01$.

compare predicted genes with the database of Kyoto Encyclopedia of Genes and Genomes (KEGG) (https://www .genome.jp/kegg/), and then identified relevant pathways for corresponding genes [24, 25]. Gene ontology annotation of the Blast2GO software (http://www.geneontology.org) was used to analyze BLAST results. The antiSMASH program (version 2.0.2) [26] was used to predict secondary metabolite gene clusters of the genome. Finally, we used the Circos software [27] to visualize the sequenced genome.

\section{Results}

3.1. The Isolation and Identification of Strain BY6. Strain BY6 was isolated from the wood stems of healthy PdPap seedlings. After culturing BY6 on LB medium at $25^{\circ} \mathrm{C}$ for 3 days, the colonies were nearly spherical with uneven surfaces, wrinkled, milky white, and odorless (Figure 1(a)). The Gramstaining result was positive, bacterial cells appeared rod- shaped, and spores were formed (Figure 1(b)). MEGA 7.0 software was used to build a phylogenetic tree based on the $16 \mathrm{~S}$ rRNA gene sequence obtained (Figure 1(c)). Strain BY6 belonged to the same genus branch as $B$. velezensis (NR075005.2) and B. velezensis (NR116240.1) exhibiting the closest genetic distance to B. velezensis (NR116240.1), with a support rate of $97 \%$. Strain BY6 was identified as $B$. velezensis based on our experimental results.

3.2. Inhibitory Efficacy of Strain BY6. The antifungal activity of strain BY6 against A. alternata was tested. After 5 days of coculturing with $A$. alternata, a significant inhibition zone appeared (Figure 2(b)), indicating that strain BY6 inhibited A. alternata fungi, the pathogen that causes leaf blight in poplar. A high inhibition rate with a maximum of $64.59 \%$ was observed (S 1). In addition, strain BY6 can adapt to extremely cold environments such as isolated areas in the Maoer Mountain (longitude $127^{\circ} 18^{\prime} 0^{\prime \prime}$, latitude $45^{\circ} 2^{\prime} 20^{\prime \prime}$ ). 




Figure 4: A circular genome map of strain BY6. The outermost circle represents the position coordinates of the genome sequence; from outward to inward are the coding genes, gene function annotation results (including annotation result information for COG, KEGG, and GO databases), ncRNA, and genome GC content, respectively. A calculation of the GC content based on the window (chromosome length/1000) bp and step value (chromosome length/1000) bp. The red section inward indicates that the GC content in that particular region is lower than the average GC content of the whole genome, and the green part outward indicates the reverse. The higher the peak value, the greater the difference between the average GC content and the genome GC skew value. The pink section inward indicates that the content of $\mathrm{G}$ is lower than the content of $\mathrm{C}$ in that region, and the light green section outward indicates the reverse.

TABLE 1: Basic characteristics of the complete genome for strain BY6.

\begin{tabular}{lcc}
\hline Feature & Chromosome & Plasmid \\
\hline Genome size (bp) & $3,898,273$ & 7,256 \\
GC content (\%) & 47.33 & 37.53 \\
Protein-coding genes & 3,923 & 0 \\
rRNA genes & 27 & 0 \\
S rRNA genes & 9 & 0 \\
tRNA genes & 86 & 0 \\
Genomic islands & 8 & 0 \\
Prophage & 16 & 0 \\
Total number of genes & 4,045 & 0 \\
\hline
\end{tabular}

It can also withstand high temperatures of $90^{\circ} \mathrm{C}$. Consequently, BY6 is a strain of bacteria that can be potentially used as a biocide for controlling plant diseases.
3.3. Growth-Promoting Effect of Strain BY6 on Poplar. The growth-promoting effect of strain BY6 on PdPap seedlings was evaluated 30 days after inoculation with strain BY6. The overall growth of PdPap seedlings in the treatment group was significantly higher than that in the control group (Figure 3(a)). Vegetative growth indicators of aboveground and belowground parts of poplar seedlings were assessed (Figures 3(b)-3(e)). Fresh weight, plant height, and root numbers of PdPap seedlings were significantly different between the treatment and control groups $(P<0.01)$. Dry weight, leaf length, and leaf width were significantly different between the treatment and control groups $(P<0.05)$. The results indicate that BY6 has a strong plant growth promotion effect. Therefore, BY6 is a strain that can be potentially used to develop microbial fertilizers to enhance plant growth.

3.4. Genome Sequence and Genome Features of Strain BY6. The complete genome for strain BY6 comprised a circular chromosome of $3,898,273$ bp with 3,923 protein-coding genes, 27 rRNA genes, 9S rRNA genes, and 86 tRNA genes. 
COG function classification

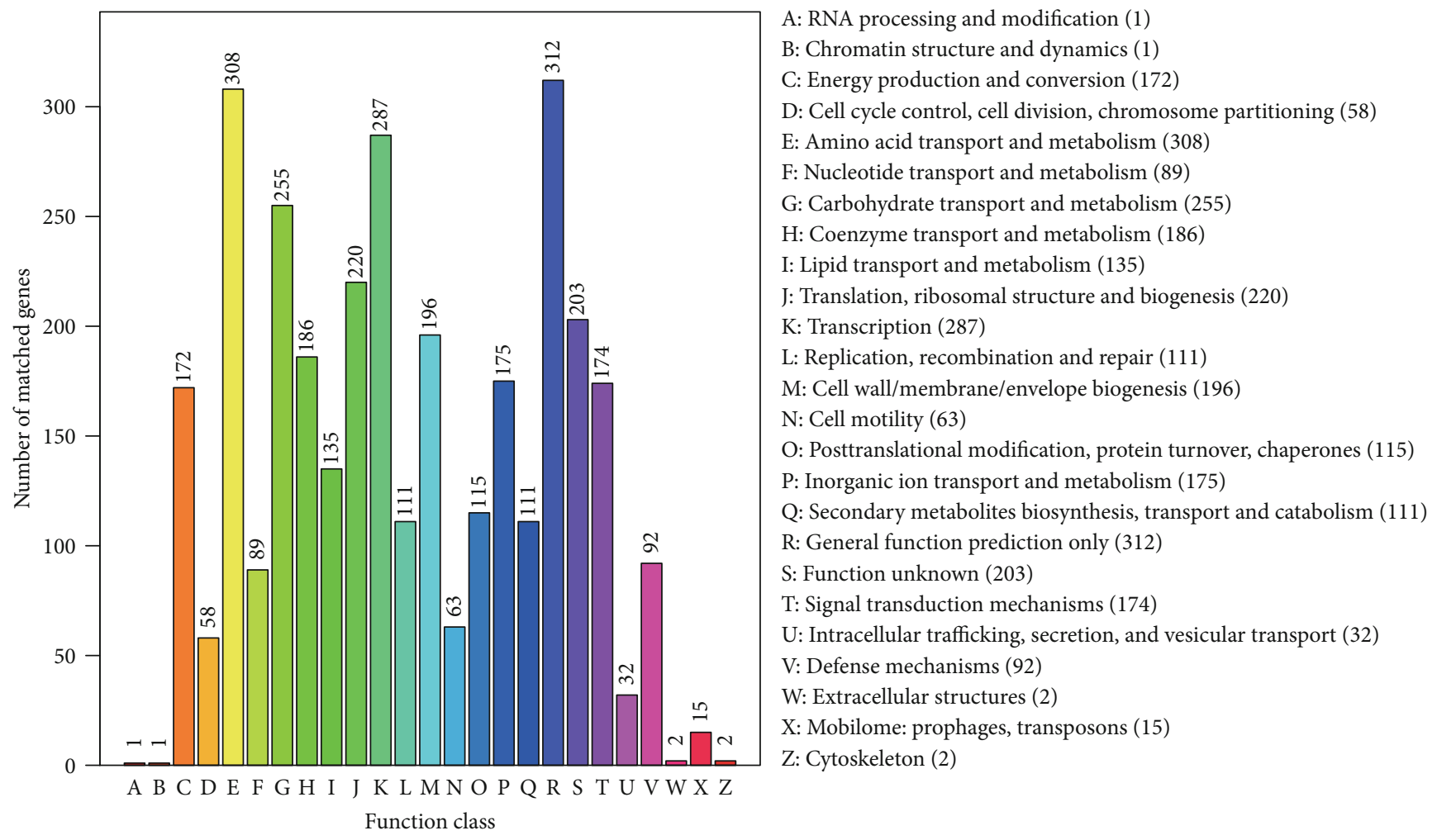

FIGURE 5: COG functional categories for the complete genome sequences of strain BY6.

The GC content of the chromosome was $47.33 \%$, with 8 gene islands and 16 prophages (Figure 4 and Table 1). The complete sequence of a circular plasmid consisted of 7,256 bp with a GC content of $37.53 \%$; three gene functions are annotated, and they are the tetratricopeptide repeat, the replication protein, and the phenazine biosynthesis-like protein ( $\mathrm{S}$ 2 and Table 1).

3.5. Genetic Basis for Production of Antimicrobial and Plant Growth-Promoting Metabolites in BY6. In the complete genome sequence of BY6, 3,315 genes were annotated with COG function, accounting for $81.95 \%$ of the complete genome sequence. The identified proteins were divided into 25 categories based on their functions (Figure 5). The functions of BY6 proteins were largely amino acid transport and metabolism (9.29\%), transcription (8.65\%), carbohydrate transport and metabolism (7.69\%), translation, ribosomal structure, and biogenesis (6.63\%). The numbers of coding genes were $308,287,255$, and 220. A total of 312 gene proteins were classified as general function prediction only, while the functions of 203 gene proteins were unknown.

We also established that 599 related genes were involved in the bacteriostasis and biosynthesis of secondary metabolites. Analysis of the secondary metabolites of BY6 revealed that there were 9 gene clusters with antibacterial properties (Table 2). Gene clusters were chiefly responsible for anabolic metabolism. The secondary metabolites with potential antibacterial properties included surfactin, bacillibactin, pelgi- peptin, bacillolysin, polyketide, bacitracin, macrolactin, and bacillaene, which may be responsible for inhibiting growth of fungal hyphae in A. alternata.

A comparison of the BY6 genome sequence with the other three complete genome sequences of this species, LPL-K103 [28], FZB42 [29], and QST713 [30], revealed that the chief gene clusters that produce bacteriostatic secondary metabolites were generally similar. They included biosynthetic gene clusters of surfactin, bacillibactin, pelgipeptin, bacillolysin, polyketide, bacitracin, macrolactin, and bacillaene. However, the biosynthesis gene for sphingosine only occurs in bacterial strain BY6. The strain BY6 has seven other gene clusters associated with secondary metabolism, and their functions are unknown. Moreover, certain enzyme genes linked with antibiotic synthesis such as glucanase, ribonuclease, chitosanase, and peptidoglycanase genes have been characterized in strain BY6.

The BY6 genome contains numerous genes that promote plant growth. We postulated that one secondary metabolic gene cluster produces ferredoxin, a strong iron carrier that increases absorption of iron ions from the soil. BY6 also contains a few other related genes that promote plant growth, including encoding butanone and polyketide among others. Furthermore, BY6 has genes responsible for nitrogen fixation. Therefore, the host plant can absorb these substances to complete its auxin biosynthesis process. Auxin biosynthesis is instrumental in the growth and development of the roots, stems, and leaves of PdPap. 
TABLe 2: Potential gene clusters encoding secondary metabolites in BY6.

\begin{tabular}{|c|c|c|c|c|c|}
\hline Number & Cluster category & $\begin{array}{l}\text { Metabolite } \\
\text { Unknown }\end{array}$ & Position & Function & Reference \\
\hline 1 & Nrps & $\begin{array}{c}\text { Surfactin } \\
\text { Bacillibactin }\end{array}$ & GM000322-GM000370 & $\begin{array}{c}\text { Sideropore } \\
\text { Antimicrobial }\end{array}$ & {$[36,37]$} \\
\hline 2 & Lantipeptide & Pelgipeptin & GM001260-GM001391 & Antimicrobial & {$[38]$} \\
\hline 3 & Transatpks & Bacillolysin & GM001490-GM001534 & Antifungal & [39] \\
\hline 4 & Transatpks-nrps & Polyketide & GM001772-GM001824 & Antimicrobial & {$[39]$} \\
\hline 5 & Transatpks-nrps & Bacitracin & GM002910-GM002920 & Antimicrobial & [39] \\
\hline 6 & Transatpks & $\begin{array}{l}\text { Polyketide } \\
\text { Macrolactin }\end{array}$ & GM002309-GM002366 & Antibacterial & {$[28,40]$} \\
\hline 7 & Bacteriocin-nrps & Bacillaene & GM003051-GM003119 & $\begin{array}{l}\text { Antibacterial } \\
\text { Sideropore }\end{array}$ & {$[16,41]$} \\
\hline 8 & Other & Unknown & GM003682-GM003729 & & \\
\hline 9 & Thiopeptide & Unknown & GM000628-GM000652 & & \\
\hline 10 & Others & Unknown & GM000967-GM001012 & & \\
\hline 11 & Terpene & Unknown & GM001095- GM001120 & & \\
\hline 12 & Terpene & Unknown & GM001998-GM002021 & & \\
\hline 13 & t3pks & Unknown & GM002118-GM002170 & & \\
\hline
\end{tabular}

\section{Discussion}

PdPap is one of the most widely planted tree species in China. Various fungal diseases of plant leaves are increasingly occurring with the continuous expansion of PdPap plantations and degradation of the environment, adversely affecting the growth of PdPap. In the present study, the bacterial strain BY6 was isolated from PdPap. Biologically controlled experiments were performed, and results demonstrated that the strain BY6 can inhibit the growth of mycelia of the leaf blight pathogen in PdPap and promote the growth of PdPap seedlings. The endophytic bacterial strain BY6 was isolated from healthy PdPap wood stems. A few studies have indicated that PGPB, which have coevolved with the host plants or are compatible with growth environments, are beneficial to plants. Moreover, PGPB will not cause substantial damage to the host plants, but it can establish a harmonious symbiotic relationship with the host plant [31].

We sequenced the complete genome of bacterial strain BY6 to study its genetic basis and molecular mechanism. We characterized 9 secondary metabolite gene clusters that can inhibit the growth of A. alternata. Bacilysin is one of the simplest peptide antibiotics secreted by certain species of Bacillus [32]. Bacillaene is a polyene antibacterial substance secreted by Bacillus [33]. Surfactin and fengycin are broad-spectrum antibacterial substances present in several Bacillus species, and their antibacterial activity has been widely reported [34]. In addition, other genes that can promote plant growth have been identified in strain BY6. There was a similar work on the compounds from Bacillus amyloliquefaciens BAS23 that have antifungal activity and plant growth-promoting activity [35]. Genomic information of BY6 will facilitate identification of more active secondary metabolites, which may exhibit strong antibacterial activity against different types of pathogenic bacteria. This is an indi- cation that the strain BY6 has the potential of being used as a biological control agent in the future. Our results further serve as a basis for developing new biocontrol agents or microbial fertilizers using $B$. velezensis.

\section{Data Availability}

The available complete genome sequence has been admitted to $\mathrm{DDBJ} / \mathrm{NCBI} / \mathrm{EMBL}$ databases, the received accession numbers is CP051011-CP051012.

\section{Conflicts of Interest}

The authors declare that they have no conflict of interest.

\section{Acknowledgments}

This study was supported and funded by the Fundamental Research Funds for the Central Universities (2572019AB19) and the Special Project for Double First-Class-Cultivation of Innovative Talents (000/41113102). Thanks are due to Beijing Novogene Science and Technology Corporation for their help in genome sequencing in this study.

\section{Supplementary Materials}

Supplementary 1. Supplementary S1: the effect of strain BY6 on the colony growth inhibition rate of Alternaria alternata.

Supplementary 2. Supplementary S2: a circular plasmid map of strain BY6.

\section{References}

[1] Y. Sun, S. Chen, H. Huang, J. Jiang, S. Bai, and G. Liu, "Improved salt tolerance of Populus davidiana $\times P$. bolleana 
overexpressed LEA from Tamarix androssowii," Journal of Forestry Research, vol. 25, no. 4, pp. 813-818, 2014.

[2] E. Osdaghi and N. Rahimi Kakavandi, "A new leaf disease onPopulus euphraticain south-western Iran," Forest Pathology, vol. 45, no. 4, pp. 336-341, 2015.

[3] I. T. Paulsen, C. M. Press, J. Ravel et al., "Complete genome sequence of the plant commensal Pseudomonas fluorescens Pf-5," Nature Biotechnology, vol. 23, no. 7, pp. 873-878, 2005.

[4] R. Thilagam and N. Hemalatha, "Plant growth promotion and chilli anthracnose disease suppression ability of rhizosphere soil Actinobacteria," Journal of Applied Microbiology, vol. 126, no. 6, pp. 1835-1849, 2019.

[5] S. Gouda, G. Das, S. K. Sen, H. S. Shin, and J. K. Patra, "Endophytes: a treasure house of bioactive compounds of medicinal importance," Frontiers in Microbiology, vol. 7, article 1538, 2016.

[6] J. Zhang, P. Wang, H. Tian, H. Jiang, Y. Wang, and C. Yan, "Identification of interior salt-tolerant bacteria from ice plant Mesembryanthemum crystallinum and evaluation of their promoting effects," Symbiosis, vol. 76, no. 3, pp. 243-252, 2018.

[7] A. Chinnaswamy, T. Coba de la Peña, A. Stoll et al., "A nodule endophyticBacillus megateriumstrain isolated fromMedicago polymorphaenhances growth, promotes nodulation byEnsifer medicaeand alleviates salt stress in Alfalfa plants," Annals of Applied Biology, vol. 172, no. 3, pp. 295-308, 2018.

[8] N. X. Feng, J. Yu, C. H. Mo et al., "Biodegradation of di-n-butyl phthalate (DBP) by a novel endophytic Bacillus megaterium strain YJB3," Science of the Total Environment, vol. 616-617, pp. 117-127, 2018.

[9] M. G. Wright and G. M. Bennett, "Evolution of biological control agents following introduction to new environments," BioControl, vol. 63, no. 1, pp. 105-116, 2018.

[10] R. J. Cook, "Making greater use of introduced microorganisms for biological control of plant pathogens," Annual Review of Phytopathology, vol. 31, no. 1, pp. 53-80, 1993.

[11] S. Selim, F. Martin-Laurent, N. Rouard, S. Gianinazzi, and D. van Tuinen, "Impact of a new biopesticide produced by Paenibacillus sp. strain B2 on the genetic structure and density of soil bacterial communities," Pest Management Science, vol. 63, no. 3, pp. 269-275, 2007.

[12] K. F. Baker, "Evolving concepts of biological control of plant pathogens," Annual Review of Phytopathology, vol. 25, no. 1, pp. 67-85, 1987.

[13] M. S. Attia, G. S. El-Sayyad, M. Abd Elkodous, and A. I. ElBatal, "The effective antagonistic potential of plant growthpromoting rhizobacteria against Alternaria solani -causing early blight disease in tomato plant," Scientia Horticulturae, vol. 266, p. 109289, 2020.

[14] I. Martinez-Raudales, Y. De La Cruz-Rodriguez, A. AlvaradoGutierrez et al., "Draft genome sequence of Bacillus velezensis 2A-2B strain: a rhizospheric inhabitant of Sporobolus airoides (Torr.) Torr., with antifungal activity against root rot causing phytopathogens," Standards in Genomic Sciences, vol. 12, no. 1, p. 73, 2017.

[15] L. Huang, Q. C. Li, Y. Hou et al., "Bacillus velezensis strain HYEB5-6 as a potential biocontrol agent against anthracnose on Euonymus japonicus," Biocontrol Science and Technology, vol. 27, no. 5, pp. 636-653, 2017.

[16] Q. Meng, H. Jiang, and J. J. Hao, "Effects of Bacillus velezensis strain BAC03 in promoting plant growth," Biological Control, vol. 98, pp. 18-26, 2016.
[17] S. Yamamoto and S. Harayama, "PCR amplification and direct sequencing of gyrb genes with universal primers and their application to the detection and taxonomic analysis of Pseudomonas putida strains," Applied and Environmental Microbiology, vol. 61, no. 10, article 3768, 1995.

[18] S. Kumar, M. Nei, J. Dudley, and K. Tamura, "MEGA: a biologist-centric software for evolutionary analysis of DNA and protein sequences," Briefings in Bioinformatics, vol. 9, no. 4, pp. 299-306, 2008.

[19] L. Chernin, Z. Ismailov, S. Haran, and I. Chet, "Chitinolytic Enterobacter agglomerans antagonistic to fungal plant pathogens," Applied and Environmental Microbiology, vol. 61, no. 5, pp. 1720-1726, 1995.

[20] M. E. S. Hernández, A. R. Dávila, A. P. de Algaba, M. A. B. López, and A. T. Casas, "Occurrence and etiology of death of young olive trees in southern Spain," European Journal of Plant Pathology, vol. 104, no. 4, pp. 347-357, 1998.

[21] J. Reiner, L. Pisani, W. Q. Qiao et al., "Cytogenomic identification and long-read single molecule real-time (SMRT) sequencing of a Bardet -Biedl Syndrome 9 (BBS9) deletion," Genomic Medicine, vol. 3, no. 1, p. 3, 2018.

[22] J. Besemer, A. Lomsadze, and M. Borodovsky, "GeneMarkS: a self-training method for prediction of gene starts in microbial genomes. Implications for finding sequence motifs in regulatory regions," Nucleic Acids Research, vol. 29, no. 12, pp. 2607-2618, 2001.

[23] M. Y. Galperin, K. S. Makarova, Y. I. Wolf, and E. V. Koonin, "Expanded microbial genome coverage and improved protein family annotation in the COG database," Nucleic Acids Research, vol. 43, no. D1, pp. D261-D269, 2015.

[24] M. Kanehisa, S. Goto, S. Kawashima, Y. Okuno, and M. Hattori, "The KEGG resource for deciphering the genome," Nucleic Acids Research, vol. 32, no. 90001, pp. 277D-2280, 2004.

[25] M. Kanehisa, S. Goto, M. Hattori et al., "From genomics to chemical genomics: new developments in KEGG," Nucleic Acids Research, vol. 34, no. 90001, pp. D354-D357, 2006.

[26] M. H. Medema, K. Blin, P. Cimermancic et al., “AntiSMASH: rapid identification, annotation and analysis of secondary metabolite biosynthesis gene clusters in bacterial and fungal genome sequences," Nucleic Acids Research, vol. 39, Supplement_2, pp. W339-W346, 2011.

[27] M. Krzywinski, J. Schein, I. Birol et al., "Circos: an information aesthetic for comparative genomics," Genome Research, vol. 19, no. 9, pp. 1639-1645, 2009.

[28] Y. Zhang, Y. Wang, Y. Qin, and P. L. Li, "Complete genome sequence of Bacillus velezensis LPL-K103, an antifungal cyclic lipopeptide bacillomycin 1 producer from the surface of lemon," 3 Biotech, vol. 10, no. 1, p. 8, 2020.

[29] F. Peypoux, F. Besson, G. Michel, and L. Delcambe, "Structure of bacillomycin D, a new antibiotic of the iturin group," European Journal of Biochemistry, vol. 118, no. 2, pp. 323-327, 1981.

[30] F. Peypoux, M. T. Pommier, B. C. Das, F. Besson, L. Delcambe, and G. Michel, "Structures of bacillomycin D and bacillomycin L peptidolipid antibiotics from Bacillus subtilis," Journal of Antibiotics, vol. 37, no. 12, pp. 1600-1604, 1984.

[31] H. Etesami and H. A. Alikhani, "Rhizosphere and endorhiza of oilseed rape (Brassica napus L.) plant harbor bacteria with multifaceted beneficial effects," Biological Control, vol. 94, pp. 11-24, 2016. 
[32] G. Ozcengiz and I. Ogulur, "Biochemistry, genetics and regulation of bacilysin biosynthesis and its significance more than an antibiotic," New Biotechnology, vol. 32, no. 6, pp. 612-619, 2015.

[33] R. A. Butcher, F. C. Schroeder, M. A. Fischbach et al., "The identification of bacillaene, the product of the PksX megacomplex in Bacillus subtilis," Proceedings of the National Academy of Sciences of the United States of America, vol. 104, no. 5, pp. 1506-1509, 2007.

[34] M. Farzaneh, Z. Q. Shi, M. Ahmadzadeh, L. B. Hu, and A. Ghassempour, "Inhibition of the Aspergillus flavus growth and aflatoxin B1 contamination on pistachio nut by fengycin and surfactin-producing Bacillus subtilis UTBSP1," Plant Pathology, vol. 32, no. 3, pp. 209-215, 2016.

[35] S. Saechow, A. Thammasittirong, P. Kittakoop, S. Prachya, and S. N. R. Thammasittirong, "Antagonistic activity against dirty panicle rice fungal pathogens and plant growth-promoting activity of Bacillus amyloliquefaciens BAS23," Journal of Microbiology and Biotechnology, vol. 28, no. 9, pp. 15271535, 2018.

[36] X. H. Chen, A. Koumoutsi, R. Scholz et al., "Comparative analysis of the complete genome sequence of the plant growthpromoting bacterium Bacillus amyloliquefaciens FZB42," Nature Biotechnology, vol. 25, no. 9, pp. 1007-1014, 2007.

[37] H. Jeong, D. E. Jeong, S. H. Park, S. J. Kim, and S. K. Choi, "Complete genome sequence of Bacillus Subtilis strain WB800N, an extracellular protease-deficient derivative of strain 168," Microbiology Resource Announcements, vol. 7, no. 18, p. 18, 2018.

[38] C. D. Qian, T. Z. Liu, S. L. Zhou et al., "Identification and functional analysis of gene cluster involvement in biosynthesis of the cyclic lipopeptide antibiotic pelgipeptin produced by $\mathrm{Pae}$ nibacillus elgii," BMC Microbiology, vol. 12, no. 1, p. 197, 2012.

[39] K. Schneider, X. H. Chen, J. Vater et al., "Macrolactin is the polyketide biosynthesis product of the pks 2 cluster of Bacillus amyloliquefaciens FZB42," Journal of Natural Products, vol. 70, no. 9, pp. 1417-1423, 2007.

[40] C. Jaruchoktaweechai, K. Suwanborirux, S. Tanasupawatt, P. Kittakoop, and P. Menasveta, "New macrolactins from a marine Bacillus sp Sc026," Journal of Natural Products, vol. 63, no. 7, pp. 984-986, 2000.

[41] J. Xie, H. Shi, Z. du, T. Wang, X. Liu, and S. Chen, "Comparative genomic and functional analysis reveal conservation of plant growth promoting traits in Paenibacillus polymyxa and its closely related species," Scientific Reports, vol. 6, no. 1, p. 21329, 2016. 